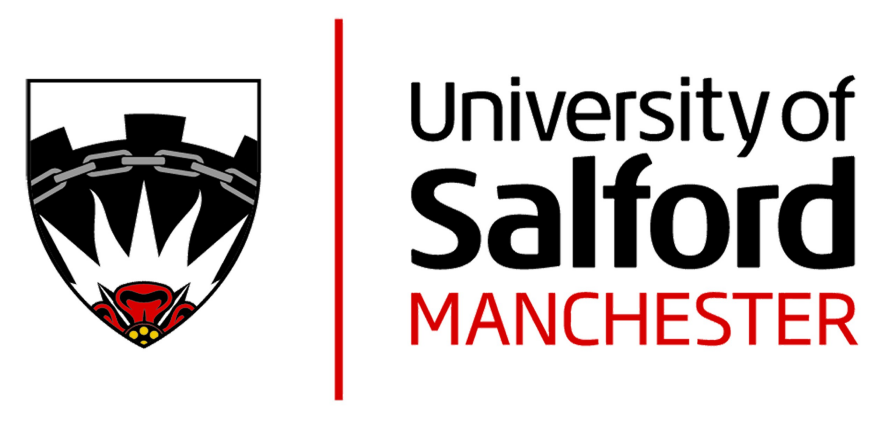

\title{
An exploration of the attitudes and perceptions of the UK public towards self-care for minor ailments
}

\author{
Scott, Ashley and Jones, Colin \\ 10.12968 /bjon.2020.29.1.44
}

\begin{tabular}{|l|l|}
\hline Title & $\begin{array}{l}\text { An exploration of the attitudes and perceptions of the UK } \\
\text { public towards self-care for minor ailments }\end{array}$ \\
\hline Authors & Scott, Ashley and Jones, Colin \\
\hline Type & Article \\
\hline URL & $\begin{array}{l}\text { This version is available at: } \\
\text { http://usir.salford.ac.uk/id/eprint/56279/ }\end{array}$ \\
\hline Published Date & 2020 \\
\hline
\end{tabular}

USIR is a digital collection of the research output of the University of Salford. Where copyright permits, full text material held in the repository is made freely available online and can be read, downloaded and copied for noncommercial private study or research purposes. Please check the manuscript for any further copyright restrictions.

For more information, including our policy and submission procedure, please contact the Repository Team at: $\underline{\text { usir@salford.ac.uk. }}$ 


\title{
Exploration of the attitudes and perceptions of the UK public towards self-care for minor ailments.
}

\author{
Ashley J. S. Scott, MSc Student ${ }^{1}$ \\ Dr Colin P. Jones, Senior Lecturer/Researcher ${ }^{2}$
}

${ }^{1}$ School of Nursing and Allied Health, Liverpool John Moores University, Liverpool

${ }^{2}$ School of Nursing and Allied Health, Liverpool John Moores University, Liverpool

Corresponding author: Ashley Scott, ashleyjsscott@gmail.com

\section{ABSTRACT}

Aims and objectives: The purpose of this pilot study was to explore the attitudes and perceptions of members of the UK public towards self-care for minor ailments.

Background: With an ageing and increasing population, and a National Health Service in extremis with plummeting performance indicators and the huge disparity between available funding and costs of treatments, methods to reduce demand upon health services are key. Increasing the use of self-care for minor ailments is one way in which this pressure could be alleviated.

Design + Method: This study utilised qualitative methods including semi-structured telephone interviews. This data was then evaluated, and key themes are drawn out of the data using thematic analysis.

Findings: The results showed that the public are aware of the notion of self-care, and some are engaging with it. However, for a number of reasons, patients are still likely to want a face to face appointment despite the use of internet and telephone advice services.

Conclusion: The study highlighted that there are multifactorial aspects impacting upon a patient's likelihood to engage in self-care when faced with a minor illness. The results are not generalisable to every member of the UK public, but interesting questions are raised with regards to the usefulness of current public health messages being portrayed across various media when there appears to be a lack of desire from the public to use some recommended services. 


\section{ABSTRACT}

Aims and objectives: The purpose of this pilot study was to explore the attitudes and perceptions of members of the UK public towards self-care for minor ailments.

Background: With an ageing and increasing population, and a National Health Service in extremis with plummeting performance indicators and the huge disparity between available funding and costs of treatments, methods to reduce demand upon health services are key. Increasing the use of self-care for minor ailments is one way in which this pressure could be alleviated.

Design + Method: This study utilised qualitative methods including semi-structured telephone interviews. This data was then evaluated, and key themes are drawn out of the data using thematic analysis.

Findings: The results showed that the public are aware of the notion of self-care, and some are engaging with it. However, for a number of reasons, patients are still likely to want a face to face appointment despite the use of internet and telephone advice services.

Conclusion: The study highlighted that there are multifactorial aspects impacting upon a patient's likelihood to engage in self-care when faced with a minor illness. The results are not generalisable to every member of the UK public, but interesting questions are raised with regards to the usefulness of current public health messages being portrayed across various media when there appears to be a lack of desire from the public to use some recommended services.

Key Phrases: This article looks at the reasons why the public may choose not to engage in self-care methods. The context is that of an increasing demand upon the health service which could be alleviated by better self-care. It identifies a number of barriers to self-care for minor ailments. Recommendations are made for future practice.

Key Words: Self Care, Access to Healthcare, General Practice, United Kingdom, Nursing 


\section{Background + Literature Review:}

The population of the United Kingdom continues to grow, and with it, we have an ageing population. It is predicted that by the year 2047 the population will have increased to over 76,342,235 and that 24.7 per cent of this population will be over the age of 65 (Office for National Statistics, 2017).

The National Health Service (NHS) is already experiencing unprecedented pressures, with deteriorating performance indicators (The King's Fund, 2018) and an ever-increasing chasm between the cost of treatments and the funding available (Gainsbury, 2017). It is highly probable that this growth in numbers and the ageing population will only exacerbate these problems in years to come. In its most recent review of NHS performance, The King's Fund (2018) asked Clinical Commissioning Group (CCG) finance leads how confident they were about the ability of General Practice to meet demand - 67 per cent of CCGs felt concerned or very concerned.

If general practice can be seen as the gateway to the health service, then unachievable targets with regards to capacity have a knock-on effect on the NHS as a whole. There is an increasing trend towards patients attending their GP with minor illness which could be managed at home before medical review is needed (Baird et al, 2016). Understanding the reasons behind this may take us closer to enabling people to feel confident in their own ability to self-care, reducing some of the pressures on the NHS.

A literature review was carried out using the terms 'self-care' AND "minor illness' OR 'minor ailments", focused on peer-reviewed journals relating to the UK health care setting from the last ten years.

Nineteen relevant articles were found which directly related to the research question. Three papers were informative guides on how to self-care for three specific minor ailments, rather than reviewing whether or not people might engage in self-care and the reasons for this (Schroeder and Richards, 2012a; Schroeder and Richards, 2012b; Schroeder and Richards, 2013). Richards (2009; 2010) championed the role of the practice nurse in empowering patients to self-care but again did not address the thoughts and feelings behind why patients may or may not take this guidance on board. This concept was echoed by Robinson (2007; 2009; 2010; 2011) and Cross (2011), championing the benefits of patient self-care, but again the barriers to successful engagement with self-care were not addressed. One research protocol found looked to be promising but related only to the self-care of patients managing their chronic conditions (Bower et al, 2012).

Ryan et al (2009) carried out a systematic review of the literature from the preceding fifteen years. They found that users of self-care methods were most likely to be middle-aged affluent females, but 
there was no exploration into the reasons for this. With a lack of literature looking at the reasoning behind why people may choose not to engage with self-care techniques, a gap in the research was identified that the author felt was worth exploring.

\section{Method:}

This was a pilot study aiming to provide a snapshot of data which could lead to further investigation in the future.

\section{Research Question:}

The aim of this study was to explore the attitudes and perceptions of the UK public towards self-care for minor ailments.

\section{Participants + Recruitment:}

Participants were recruited through an online platform called 'Call for Participants' (Call for Participants, 2018). The site was developed in order to give researchers a platform for showcasing their studies to a wider audience.

Inclusion criteria were that participants were current UK residents over the age of 18 . This was to allow for sampling across the age spectrum, whilst recruiting participants who would have direct experience of the UK healthcare services.

\section{Ethics:}

Ethical permission was sought and obtained. Austin (2006, pg. 359) identifies that ethical practice is an important issue across nursing as a whole, and not just applicable to those involved in research. This is echoed by the Nursing and Midwifery Council's Code (2015) which directs that registrants must 'make sure that any... publications or published material you produce or have produced for your professional services are... ethical'.

The author feels that the principles of ethics extend beyond our professional lives and into our personal, so high regard was placed upon ensuring no harm came to participants. The six ethical principles proposed by the International Council of Nurses (2003) of beneficence, non-maleficence, fidelity, justice, veracity and confidentiality were considered as part of the research development process.

The key ethical issue concerning this piece of research was confidentiality, where great care was taken to protect the participants' data. Also, although the interviews were deliberately designed to not encourage participants to divulge sensitive information regarding their healthcare history, 
signposting information was given to participants before they consented to take part in case any distress was caused.

\section{Sample:}

Eight expressions of interest were received through the recruitment website. One potential participant decided not to proceed to interview, and another had applied twice. Therefore, six participants signed and returned consent forms and proceeded to take part in the study. No demographic data was collected from participants which is addressed in the limitations section below.

\section{Data Collection:}

Semi-structured interviews were carried out (Kvale and Brinkmann, 2009), with questions having been revised following a trial interview carried out before true data collection started. This style was chosen to allow the researcher to guide the conversation so specific topics were covered, whilst allowing participants to answer from their own perspective and to reflect upon their own experiences (Holland and Rees, 2010, pg.81).

\section{Data Analysis:}

Audio data was transcribed immediately after an interview took place. The researcher played back the audio file and the conversation was transcribed verbatim. The interview was then played once again to allow the researcher to ensure that the written data was a true and valid reflection of the conversation that had taken place.

Qualitative content analysis was performed in order to identify themes within the data from which to draw conclusions (Graneheim and Lundman, 2004). In order to fully immerse himself in the data, the researcher read through each interview in full twice before proceeding any further. Then the data was reviewed again, and notes were recorded where any theme appeared to recur throughout the interviews. Once the themes had been identified the data were manually coded into units. The researcher then grouped units from different participants together in order to better visualise and understand what was being discussed with regard to each theme.

\section{Results:}

Participants engaged well with telephone interviews. They all had experience of using self-care methods, even if some had not heard of the term 'self-care' before. An interesting range of viewpoints were gathered and a number of key themes were extrapolated from the data, which are explored below. 


\section{Current Use of Self-Care}

Participants had a good grasp of what the term 'self-care' encompassed. Interestingly, many participants mentioned the impact of self-care on their mental health, which the author had not considered to be within the scope of this study. Diet, exercise and stress management were all identified as contributing to a healthy lifestyle, and therefore were considered to fall under the umbrella of self-care.

Practical methods of self-care were discussed and included taking painkillers, looking at practical causes for ailments, such as potential allergens when experiencing a rash, rest and the therapeutic use of time to allow illness to pass.

'I'd probably wait two or three days and see how I felt after that.'

The time aspect was not always in accordance with what current literature might feel is an appropriate time for a self-limiting illness to need to pass.

'Who likes going to the doctors? Nobody does...'

Keeping out of the GP surgery was an aim for all participants. Partly because of the fact that GP's were perceived as being very busy, and so should not be disturbed from dealing with patients with more serious problems. It was, however, noted by some participants that this view might not be shared by all.

'I wouldn't dream of going and... 'Oh well, I've got a cold, can you give me some cough medicine and some painkillers?', I just wouldn't do that'.

The Internet

$$
\text { 'Erm... Oh God, well, Dr Google...' }
$$

The internet featured highly as a resource for self-care advice, however, it was not always perceived as being the most trustworthy source. There was recognition amongst participants that there may be some high-quality, evidence-based information available. The NHS Choices (National Health Service, 2018) website drew many comments referencing it as a reliable source of information. Participants did indicate that whilst they are aware of the most useful sources of information, they were liable to be side-tracked into looking at information which may not give them the advice and reassurance they require. 
'It would probably tell me that I had meningitis'

'I saw one the other day which was some guy who had been recommended to use his own urine to treat an eye infection'

'I was doing the whole Google Image thing and I just saw all sorts of weird cancers and whatnot' Well-meaning public discussion forums, such as MumsNet, were referred to as both a distraction from good medical advice liable to result in 'panic-mode' for some, as well as a primary source of information for other participants.

\section{The Telephone}

The use of telephone advice featured heavily in the interviews, with all participants able to recount some kind of experience of services. Respondents had mixed feelings regarding the utility of telephone advice services.

'They dealt with it very well and they gave some really good advice'

'It seems a bit pointless in my opinion'

There was a general feeling that telephone advice might be suitable for very minor questions concerning children, such as those who aren't particularly unwell but may be suffering from a mild rash. There were some concerns expressed that rather than expert clinical advice you could be faced with 'an 18-year-old reading off a script', which reduced faith in the service.

It was apparent that the outcome of the calls experienced by the participants in this study nearly all resulted in the recommendation of a face to face assessment with a clinician. This was also the preference of one participant who felt telephone advice relied too much upon the skills of the person making the call.

'they're not looking at my child... it's just kind of what I'm saying and I'm not a healthcare professional, so I don't know what I'm talking about really.'

\section{The Pharmacy}

Participants had mixed experiences of using the pharmacy for self-care advice, despite the fact that most had seen publicity over the last winter regarding the use of pharmacists as a starting point when experiencing minor illness. 
There was a general consensus that pharmacists would be capable of the assessment and treatment of rashes, and that participants might seek their advice if this was their only symptom. However, some felt that they would not utilise the services of a pharmacist for many of the other minor ailments that pharmacists are well versed in managing.

'I wouldn't... think of them as my first port of call if I was ill with a cough or something.' It was difficult for participants to pinpoint why this might be, but there was only a minority who stated they would be comfortable using the pharmacist for advice.

'I'd probably just go straight to my doctor or nurse, to be honest. I don't really know why that is, but...'

It appeared that the minor illness management aspect of a pharmacist's role may well not be well understood by the public. There may even be some misunderstanding around the level of qualifications of a Registered Pharmacist.

'I think that when it comes to my baby I just want him being seen by 'the professional' in my opinion' The ability of pharmacists to manage these patients also appears to be hampered by their working environment. They were perceived as often being too busy to consult due to the number of people waiting for prescriptions to be dispensed. Participants also felt that the environment of a pharmacy is not well suited to consulting patients about their health conditions. Even those with private rooms for consultations were frowned upon, as other members of the public in the pharmacy might think you needed to discuss an embarrassing problem.

'If you went in and then said 'can I have a word', people would know you didn't want to say it out loud...'

\section{Friends and Family}

A key theme in the author's mind, but not one reflected in the discussions with the majority of participants, is that of the use of friends and family for healthcare-related advice.

'I would probably ask my partner what he thought. And then, I would probably ask... family members, like, "Has anybody seen this before, does anybody know what it might be?".'

Only one participant indicated that they would use the pre-existing knowledge of their friends and family when faced with a minor illness. It is probably a stretch to even list this as a theme in the data, but the author felt it was an extremely surprising omission and perhaps is a theme that could be explored further in future research. 
Reasons to choose face to face

There was a general feeling throughout the interviews that a face to face appointment with a clinician was preferable, even when dealing with minor ailments.

'It kind of puts your mind at rest... at least somebody who knows what they're talking about can tell you what they think it is'

Reassurance played a key role in encouraging participants to seek a face to face appointment rather than to self-care for a period of time. Responsibility featured also, with people feeling less anxious once the responsibility for their health had been handed over to a third party.

'If anything ever were to happen... and I hadn't taken him to the doctors, I would not be able to live with myself... it's passing that responsibility on to someone else who is trained... to look out for these symptoms.'

Participants postulated that perhaps education was the key to encouraging self-care, with some participants having quite strong feelings around the subject.

'This is going to sound very rude, but I think it's a bit of a lack of intelligence. Erm... maybe, lack of experience?'

Concerns were also expressed that members of the public could be liable to abuse the system of free healthcare, with anecdotes of people using up a GP appointment in order to be prescribed analgesia which could otherwise be bought very cheaply described as a 'sad' situation.

Finally, it was apparent that participants felt that the older generation were more likely to seek a face to face appointment for a minor illness. This contradicts the author's world view, where older generations are seen as stoic, and therefore the younger generations more likely to use services. It was felt that the older generation 'get a bit more panicky' and might think 'well, I'm unwell, I'll go to the doctor' as their first option.

The idea of younger generations being more likely to tolerate symptoms and self-care for longer was challenged by another younger participant who felt that should they have tonsillitis which they felt they needed antibiotics for, they would get an urgent appointment 'because there's no point me waiting three days because then it'll have cleared up'.

Access to face to face appointments

It quickly became apparent that access to primary healthcare facilities is excellent in the UK.

'I've never not been seen on that day if I rang at 8 o'clock.' 
Every single participant stated that they were able to be seen urgently either on the day they perceived themselves to need urgent review or within 24 hours. This marries up with the expectations of the participants, many of whom felt that if they were acutely unwell, even with a minor ailment, then they should be seen within a short space of time.

'I just worry about him... so probably the next day or two days maximum.'

Most participants were able to call their surgery first thing in the morning and be booked in for that day, excepting this they would be prioritised for an appointment the following day. One participant had experience of a GP surgery which operated a daily walk-in clinic, where each registered patient believing themselves to be unwell could sit and wait for a face to face consultation on any day they chose.

The group also had experience of out-of-hours GPs and walk-in centres in their areas, increasing the potential for immediate access to services.

\section{Discussion:}

The NHS Constitution (2015) asks that the public takes personal responsibility for their own health and recognise the significant contribution people can make to their own wellbeing. Historically the NHS has been very good at funding education to allow patients with long term conditions to better care for themselves, but the author can find no evidence in the literature of large scale attempts to better educate the public to self-care when faced with a minor ailment. From personal experience of working in general practice, the author knows that the time pressures faced by clinicians do not allow for in-depth educational sessions with patients during a clinic.

Participants interestingly highlighted the internet as a source of information when trying to self-care. Importantly, they recognised that not all websites are equal which is reassuring when considering the public's ability to self-care safely.

Murray et al (2011) found in their cross-sectional study of a large sample that the use of the NHS Choices website (National Health Service, 2018) resulted in a decrease in attendances at GP surgeries for the same problem. This data was based on questionnaire results rather than evidence from primary care activity data but is likely to reflect reality for the most part. However, prior to this some of the same authors published data which indicated that being able to use the website actually helped some hard to reach groups engage better with healthcare services, resulting in an overall increase in the use of GP appointments (Nelson et al, 2010). With no clear-cut result either way, the author still feels that common sense dictates that access to high quality, free information online is likely to help the public to engage in self-care, and ongoing investment in these services is essential. 
The literature is similarly contradictory when it comes to the use of telephone services. A large randomised controlled trial (Campbell et al, 2014) found that the use of telephone triage actually increased the number of face to face consultations in the 28 days following triage. Participants in this study volunteered that they did not hold much faith in the ability of a clinician to safely perform a clinical assessment over the phone, so this is likely to be reflected in data Campbell et al (2014) gleaned in their study. Conversely, there is limited data that the public's ability to self-care can be positively influenced by telephone information and guidance (Rosen, 2014).

Participants' views on the ability of pharmacists to safely manage an episode of a minor ailment were surprising to the author. There is little in the literature to support this view and may have just been a result of the small sample size of this study. Literature exists supporting the use of the pharmacy for minor ailments (Pumtong et al, 2011). However, it also highlights issues that were noted at the start of the scheme, such as privacy, that participants in this study still found a hindrance to making good use of pharmacies today.

\section{Limitations:}

Due to relatively low interest in the study and the time constraints upon the researcher, the sample size was only very small and therefore not generalisable to the general public as a whole. However, the author is hopeful that this pilot study can generate ideas for possible future large-scale projects.

The use of a recruitment website to attract participants to take part in the research meant that the sample was not likely to be representative. Participants will have chosen to engage with the research because it was an area they were interested in, and as a result, it is possible that the participants were more likely to engage in self-care activities than other members of the public. The inclusion of a healthcare professional as a participant is likely to reflect this flaw in recruitment methodology.

No anonymised demographic data was collected as part of the study. This was a huge oversight on the part of the researcher, as comments made in interviews pertaining to other generations could have been given much more meaning with the age of participants being known. This error was only noted once the interviews were completed, and no permission to contact participants after this stage had been sought.

The lack of demonstrable representativeness of the study participants is a real threat to the reliability of the research (Green and Thorogood, 2018), and if further research is to be conducted in this area this must be addressed.

\section{Recommendations:}


The author recommends further study into why the public does not perceive pharmacists to be a valid first port of call for minor ailments, and further investment into making the pharmacy a suitable environment for carrying out consultations for minor ailment management.

A greater emphasis should be placed upon educating the public on how to self-care for minor ailments. Educational programmes should be developed and trialled in order to attract further funding for this important scheme to improve the skills of the public, which will pay dividends in the challenging future of the health service.

\section{Conclusion:}

This study demonstrates that the UK general public are aware of the notion of self-care but may not always have the knowledge or skills to carry it out. The internet and telephone triage services are being used for advice, but there is still an expectation that even a minor ailment needs a face to face review with a clinician within a small number of days. A lack of confidence in the use of pharmacists and the pharmacy environment were highlighted as reasons for reluctance to use this wellresourced service. Further large-scale study into the benefit of public education for minor illness management is recommended.

\section{References:}

Austin, W. (2006) Ethical issues in qualitative nursing research. In: Beck, C. (ed.) Routledge International Handbook of Qualitative Nursing Research. Oxon: Routledge, pp. 359-370

Baird, B., Charles, A., Honeyman, M., Maguire, D. and Das, P. (2016) Understanding pressures in general practice [online]. London: The King's Fund. Available at:

https://www.kingsfund.org.uk/sites/default/files/field/field publication file/Understanding-GPpressures-Kings-Fund-May-2016.pdf [Accessed: 13 ${ }^{\text {th }}$ May 2018]

Baqir, W., Learoyd, T., Sim, A. and Todd, A. (2011) Cost analysis of a community pharmacy 'minor ailment scheme' across three primary care trust in the North East of England. Journal of Public Health [online]. 33 (4), pp.551-555. Available at:

https://academic.oup.com/ipubhealth/article/33/4/551/1566317 [Accessed: $13^{\text {th }}$ May 2018]

Bower, P., Kennedy, A., Reeves, D., Rogers, A., Blakeman, T., Chew-Graham, C., Bowen, R., Eden, M., Gardner, C., Hann, M., Lee, V., Morris, R., Protheroe, J., Richardson, G., Sanders, C., Swallow, A. and Thomson, D. (2012) A cluster randomised controlled trial of the clinical and cost-effectiveness of a whole systems model of self-management support for the management of long-term conditions in primary care: trial protocol. Implementation Science [online]. 7 (1). Available at:

http://web.a.ebscohost.com/ehost/detail/detail?vid=0\&sid=205f3a4e-5f14-48fd-894d4093bc15f0d3\%40sessionmgr4006\&bdata=JnNpdGU9ZWhvc3QtbGI2ZQ\%3d\%3d\#AN=72443051\&db =a9h [Accessed: $15^{\text {th }}$ May 2018] 
Call for Participants (2018) Discover research fast, free and ethically! - Call for participants [online]. Available at: https://www.callforparticipants.com [Accessed: $12^{\text {th }}$ May 2018]

Campbell, J., Fletcher, E., Britten, N., Green, C., Holt, T., Lattimer, V., Richards, D., Richards, S., Salisbury, C., Calitri, R., Bowyer, V., Chaplin, K., Kandiyali, R., Murdoch, J., Roscoe, J., Varley, A., Warren, F. and Taylor, R. (2014) Telephone triage for the management of same-day consultation requests in general practice (the ESTEEM trial): a cluster-randomised controlled trial and costconsequence analysis. The Lancet [online]. 384 (9957), pp.1859-1868. Available at:

https://www.thelancet.com/journals/lancet/article/PIIS0140-6736(14)61058-8/abstract [Accessed: $13^{\text {th }}$ May 2018]

Cross, S. (2011) The role of practice nurses in educating patients to self-care. Primary Health Care [online]. 21 (7). Available at: http://web.b.ebscohost.com/ehost/detail/detail?vid=0\&sid=afcf21ede6d3-4a36-bd94-

eab900830f21\%40sessionmgr102\&bdata=JnNpdGU9ZWhvc3QtbGI2ZQ\%3d\%3d\#AN=66234121\&db= a9h [Accessed: $15^{\text {th }}$ May 2018]

Department of Health and Social Care (2015) NHS Constitution for England [online]. London: Department of Health and Social Care. Available at:

https://www.gov.uk/government/publications/the-nhs-constitution-for-england [Accessed: $13^{\text {th }}$ May 2015]

Kvale, S. and Brinkmann, S. (2009) Interviews: Learning the craft of qualitative research interviewing. California: Sage Publications

Gree, J. and Thorogood, N. (2018) Qualitative methods for health research. London: Sage Publications

Holland K., and Rees, C. (2010) Nursing: Evidence-based practice skills. Oxford: Oxford University Press

Gainsbury, S. (2017) The bottom line: Understanding the NHS deficit and why it won't go away [online]. London: Nuffield Trust. Available at: https://www.nuffieldtrust.org.uk/research/thebottom-line-understanding-the-nhs-deficit-and-why-it-won-t-go-away [Accessed: $13^{\text {th }}$ May 2018]

Graneheim, U. and Lundman, B. (2004) Qualitative content analysis in nursing research: concepts, procedures and measures to achieve trustworthiness [online]. Nurse education today. 24 (2), pp. 105-112. Available at: https://ac.els-cdn.com/S0260691703001515/1-s2.0-S0260691703001515main.pdf? tid=e61ef32d-6282-4337-a6106318cd05ffcd\&acdnat $=1526210494$ 4ce79f74d26aaf48c1f940aa38331f67 [Accessed: $12^{\text {th }}$ May 2018]

International Council of Nurses (2003) Ethical guidelines for nursing research. Geneva: International Council of Nurses

Murray, J., Majeed, A., Khan, M., Lee, J. and Nelson, P. (2011) Use of the NHS Choices website for primary care consultations: results from online and general practice surveys. Journal of the Royal Society of Medicine Short Reports [online]. 2 (7). Available at:

https://www.ncbi.nlm.nih.gov/pmc/articles/PMC3147242/ [Accessed 13 ${ }^{\text {th }}$ May 2018]

National Health Service (2018) NHS Choices Homepage [online]. Available at:

https://www.nhs.uk/pages/home.aspx [Accessed: 15 ${ }^{\text {th }}$ May 2018] 
Nelson, P., Murray, J. and Khan, M. (2010) NHS Choices Primary Care Consultation Final Report [online]. London: Imperial College. Available at:

https://www.nhs.uk/aboutNHSChoices/professionals/developments/Documents/annualreport/primary-care-consultation-report.pdf [Accessed: $13^{\text {th }}$ May 2018]

Nursing and Midwifery Council (2015) The code: professional standards of practice and behaviour for nurses and midwives. London: Nursing and Midwifery Council

Office for National Statistics (2017) Overview of the UK population: July 2017 [online]. Available at: https://www.ons.gov.uk/peoplepopulationandcommunity/populationandmigration/populationesti mates/articles/overviewoftheukpopulation/july2017 [Accessed: 12/5/2018]

Pumtong, S., Boardman, H. and Anderson, C. (2011) A multi-method evaluation of the Pharmacy First Minor Ailments scheme. International Journal of Clinical Pharmacy [online]. 33 (3), pp.578-581. Available at: https://link.springer.com/article/10.1007/s11096-011-9513-2 [Accessed: $13^{\text {th }}$ May 2018]

Richards, S. (2009) Self care in practice. Practice Nurse [online]. 37 (11). Available at:

https://search.proquest.com/docview/764388953?accountid=12118\&rfr id=info\%3Axri\%2Fsid\%3Ap rimo [Accessed: $15^{\text {th }}$ May 2018]

Richards, S. (2010) Practice nurses urged to promote patient self-care. Practice Nurse [online]. 39 (6). Available at:

https://search.proquest.com/docview/230463358?accountid=12118\&rfr id=info\%3Axri\%2Fsid\%3Ap rimo [Accessed: $15^{\text {th }}$ May 2018]

Robinson, F. (2007) Self-care initiative. Practice Nurse [online]. 34 (10). Available at:

https://search. proquest.com/docview/230457650?accountid=12118\&rfr id=info\%3Axri\%2Fsid\%3Ap rimo [Accessed: $15^{\text {th }}$ May 2018]

Robinson, F. (2009) Empowering patients to self-care. Practice Nurse [online]. 38 (10). Available at: https://search.proquest.com/docview/230466722? accountid=12118\&rfr id=info\%3Axri\%2Fsid\%3Ap rimo [Accessed: $15^{\text {th }}$ May 2018]

Robinson, F. (2010) Promoting the role of self-care. Practice Nurse [online]. 39 (10). Available at: https://search.proquest.com/docview/506148122? accountid=12118\&rfr id=info\%3Axri\%2Fsid\%3Ap rimo [Accessed: $15^{\text {th }}$ May 2018]

Robinson, F. (2011) Progress in promoting patient self-care. Practice Nurse [online]. 41 (3). Available at:

https://search.proquest.com/docview/857097856?accountid=12118\&rfr id=info\%3Axri\%2Fsid\%3Ap rimo [Accessed: $15^{\text {th }}$ May 2018]

Rosen, R. (2014) Meeting need or fuelling unnecessary demand? Understanding the impact of improved access to primary care [online]. London: Nuffield Trust and NHS England. Available at: https://www.nuffieldtrust.org.uk/files/2017-01/meeting-need-or-fuelling-demand-web-final.pdf [Accessed: $13^{\text {th }}$ May 2018]

Ryan, A., Wilson, S., Taylor, A. and Greenfield, S. (2009) Factors associated with self-care activities among adults in the United Kingdom: a systematic review. BMC Public Health [online]. 9. Available at: http://web.a.ebscohost.com/ehost/pdfviewer/pdfviewer?vid=2\&sid=a5567d5e-f4d5-4489-94d993a40a51ffe8\%40sessionmgr4006 [Accessed: 15 ${ }^{\text {th }}$ May 2018] 
Schroeder, K. and Richards, S. (2012a) Non-specific low back pain. Practice Nurse [online]. 42 (13). Available at: http://web.b.ebscohost.com/ehost/detail/detail?vid=1\&sid=f4ddfbef-1095-4c70-94f62bc2561fa35b\%40sessionmgr101\&bdata=JnNpdGU9ZWhvc3QtbGI2ZQ\%3d\%3d\#AN=79967155\&db= a9h [Accessed: $15^{\text {th }}$ May 2018]

Schroeder, K. and Richards, S. (2012b) Constipation in adults. Practice Nurse [online]. 42 (18). Available at: http://web.b.ebscohost.com/ehost/detail/detail?vid=1\&sid=3c8a061e-7323-4c7dbbeb-

227b0088ca0a\%40sessionmgr103\&bdata=JnNpdGU9ZWhvc3QtbG|2ZQ\%3d\%3d\#AN=83751684\&db= a9h [Accessed: $15^{\text {th }}$ May 2018]

Schroeder, K. and Richards, S. (2013) Acute and chronic cough. Practice Nurse [online]. 43 (2).

Available at: http://web.b.ebscohost.com/ehost/detail/detail?vid=1\&sid=fcb65783-5e0f-448a-b0542c858bea7d0f\%40sessionmgr120\&bdata=JnNpdGU9ZWhvc3QtbG|2ZQ\%3d\%3d\#AN=85803501\&db= a9h [Accessed: $15^{\text {th }}$ May 2018]

The King's Fund (2018) How is the NHS performing? March 2018 quarterly monitoring report [online]. London: The King's Fund. Available at: https://www.kingsfund.org.uk/publications/hownhs-performing-march-2018 [Accessed: $13^{\text {th }}$ May 2018] 